\title{
Neuroprotective and Memory-Enhancing Effect of the Combined Extract of Purple Waxy Corn Cob and Pandan in Ovariectomized Rats
}

\author{
Woranan Kirisattayakul,, Jintanaporn Wattanathorn, ${ }^{2,3}$ Sittichai Iamsaard, \\ Jinatta Jittiwat, ${ }^{5}$ Bhalang Suriharn, ${ }^{6}$ and Kamol Lertrat ${ }^{6}$ \\ ${ }^{1}$ Department of Physiology and Graduate School (Neuroscience Program), Faculty of Medicine, Khon Kaen University, \\ Khon Kaen 40002, Thailand \\ ${ }^{2}$ Integrative Complementary Alternative Medicine Research and Development Center, Khon Kaen University, \\ Khon Kaen 40002, Thailand \\ ${ }^{3}$ Department of Physiology, Faculty of Medicine, Khon Kaen University, Khon Kaen 40002, Thailand \\ ${ }^{4}$ Department of Anatomy, Faculty of Medicine, Khon Kaen University, Khon Kaen 40002, Thailand \\ ${ }^{5}$ Faculty of Medicine, Mahasarakham University, Maha Sarakham 44150, Thailand \\ ${ }^{6}$ Faculty of Agriculture, Khon Kaen University, Khon Kaen 40002, Thailand
}

Correspondence should be addressed to Jintanaporn Wattanathorn; jintanapornw@yahoo.com

Received 7 March 2017; Accepted 1 June 2017; Published 9 July 2017

Academic Editor: Luciano Saso

Copyright ( 2017 Woranan Kirisattayakul et al. This is an open access article distributed under the Creative Commons Attribution License, which permits unrestricted use, distribution, and reproduction in any medium, provided the original work is properly cited.

\begin{abstract}
The neuroprotectant and memory enhancer supplement for menopause is required due to the side effects of hormone replacement therapy. Since purple waxy corn cob and pandan leaves exert antioxidant and acetylcholinesterase inhibition (AChEI) effects, we hypothesized that the combined extract of both plants (PCP) might provide synergistic effect leading to the improved brain damage and memory impairment in experimental menopause. To test this hypothesis, female Wistar rats were ovariectomized bilaterally and orally given various doses of the functional drink at doses of 20,40 , and $80 \mathrm{mg} / \mathrm{kg}$ for 28 days. The animals were assessed nonspatial memory using object recognition test every 7 days throughout the study period. At the end of study, they were assessed with oxidative stress status, AChEI, neuron density, and ERK1/2 signal in the prefrontal cortex (PFC). Interestingly, all doses of PCP increased object recognition memory and neuron density but decreased oxidative stress status in PFC. Low dose of PCP also decreased AChE activity while medium dose of PCP increased phosphorylation of ERK1/2 in PFC. Therefore, the improved oxidative stress status and cholinergic function together with signal transduction via ERK in PFC might be responsible for the neuroprotective and memory-enhancing effects of PCP.
\end{abstract}

\section{Introduction}

To date, the number of menopausal women is continually growing. The World Health Organization (WHO) has estimated that the number of menopausal women worldwide will be 1200 million within 2030 [1]. It has been reported that cognitive decline is one of the important symptoms frequently observed especially in premature menopause [2]. Unfortunately, the current therapeutic strategy is still not in satisfaction level. The effect of hormone replacement therapy
(HRT) on the cognitive function of menopausal women is controversial [3-7]. In addition, serious adverse effect such as breast cancer risk is reported in HRT $[8,9]$. Therefore, the alternative strategy has gained much attention.

Among various alternative strategies, plant-based therapy is very much popular [10]. In the recent years, the use of plant-based food supplement is increased in Thailand [11]. It has been demonstrated that dietary approaches are regarded as the safe and effective preventive intervention against neurodegeneration [12]. A pile of evidence has 
revealed that consumption of the polyphenol-rich supplements can enhance memory impairment [13-15]. Recent findings have demonstrated that the purple corn (Zea mays Linn., purple color) cob, an agricultural waste, can be served as an important natural resource of polyphenol [16]. It also exhibits potent antioxidant activity and can improve oxidative stress-related disorders $[16,17]$. In addition to purple corn cob, pandan (Pandanus amaryllifolius), a commonly used culinary plant in Southeast Asia, also possesses high phenolic compound content and exhibits antioxidant activity [18]. An effervescent powder containing pandan also improves oxidative stress-related damage of the pancreas [19]. Based on these pieces of information and synergistic effect according to traditional folklore concept, the protective effect against oxidative stress-related brain damage and functional disorders of the combined extract of purple corn cob and pandan leaves (PCP) in menopausal women has been considered in order to produce an additive value of both plants. Currently, no data concerning this issue are available until now. Therefore, we aimed to determine the neuroprotective and memory-enhancing effects of the combined extract of purple corn cob and pandan leaves in experimental menopause in ovariectomized rats.

\section{Materials and Methods}

2.1. Chemicals and Reagents. Thiobarbituric acid (TBA), sodium dodecyl sulfate (SDS), glacial acetic acid, N-butanol, pyridine, 1,3,3-tetraethoxypropane (TEP), cytochrome C, xanthine oxidase, xanthine, glutathione reductase, nicotinamide adenine dinucleotide phosphate (NADPH), hydrogen peroxide, superoxide dismutase, glutathione peroxidase, catalase, acetylthiocholine iodide (ATCI), acetylcholinesterase, 5,5'-dithiobis (2-nitrobenzoic acid) (DTNB), cresyl violet, sodium acetate, sodium carbonate, 2,4,6-tripyridyl-striazine (TPTZ), Folin-Ciocalteu reagent, gallic acid, ascorbic acid, Trizma hydrochloride, potassium chloride, 2,2-diphenyl-1picrylhydrazyl (DPPH), tris-hydrochloride, and sodium carbonate were purchased from Sigma-Aldrich (St. Louis, MO, USA). Chemicals used in Western blot analysis were purchased from Bio-Rad Laboratories. Methanol and acetic acid (HPLC grade) were purchased from Fisher Scientific.

2.2. Plant Material Preparation and Extraction. The cobs of purple waxy corn (Zea mays, open-pollinated cultivar) harvested during November-December 2012 were identified and kindly provided by Professor Kamol Lertrat and Assistant Professor Bhalang Suriharn, Department of Plant Science and Agricultural Resources, Faculty of Agriculture, Khon Kaen University, Khon Kaen, Thailand. Pandan (Pandanus amaryllifolius) leaves were harvested at the same period as Z. mays from the Khon Kaen province. The plant identification was performed by Mister Winai Somprasong, an expert agricultural scientist in the Botany and Plant Herbarium research group, Plant Varieties Protection Division, Ministry of Agriculture and Cooperatives. The cobs of $Z$. mays and the leaves of $P$. amaryllifolius were cleaned and cut into a small pieces; then, they were force dried by using an oven at $60^{\circ} \mathrm{C}$ overnight. The dried plants (2 kilograms of each plant) were twice extracted with 5 liters of distilled water. The percent yield of $Z$. mays and $P$. amaryllifolius were 2.4 and 8 , respectively.

2.3. Preparation of a Polyphenol-Rich Functional Drink. Powder of various ingredients including 2\% $(w / v)$ combined extract of $Z$. mays and $P$. amaryllifolius (a ratio of both extracts was obtained from our unpublished in vitro data which provided optimum potential and under petit patent), $0.75 \%(v / v)$ sucralose, $1 \%(v / v)$ lemonade, $0.025 \%(w / v)$ salt, and $96.225 \%(v / v)$ water. All ingredients were mixed together and filtered through a cheesecloth, and the filtrate was used for further study.

2.4. Determination of Total Phenolic Compound Contents. The determination of total phenolic compounds content was carried out by using the Folin-Ciocalteu method [20]. In brief, an aliquot of combined extract beverage $(20 \mu \mathrm{l})$ was added to distilled water $(1.58 \mathrm{ml})$ and $50 \%(v / v)$ Folin-Ciocalteu phenol reagent $(0.1 \mathrm{ml})$ (Sigma-Aldrich). After 8 minutes of incubation, $20 \%$ sodium carbonate $(0.3 \mathrm{ml})$ was added and mixed well. The mixture was kept in a dark room and incubated for 2 hours at room temperature. The absorbance was measured at $765 \mathrm{~nm}$ with a UVspectrophotometer (Pharmacia LKB-Biochrom4060). Gallic acid at concentrations of $50-600 \mathrm{mg} / \mathrm{l}$ were used for preparing the standard calibration curve. The total phenolic compound was expressed as gallic acid equivalents per $\mathrm{mg}$ extract (mg/l GAE).

2.5. Assessment of DPPH Inhibition. The scavenging activity against free radicals of the developed drink was assessed via $\mathrm{DPPH}$ assessment. Briefly, $0.15 \mathrm{mM}$ DPPH in methanol $(0.5 \mathrm{ml})$ and the functional drink $(1 \mathrm{ml})$ were mixed and incubated at room temperature for 30 minutes. The absorbance was determined at $517 \mathrm{~nm}$ with a UVspectrophotometer (Pharmacia LKB-Biochrom4060). The DPPH radical scavenging activity was calculated using the following equation:

\%Inhibition of DPPH $=\left[\left(\frac{\text { Abs control }- \text { Abs sample }}{\text { Abs control }}\right)\right] \times 100$.

Abs control was the absorbance of methanol plus DPPH reagent while Abs sample was the absorbance of developed drink or standard. The linear portion of percentage inhibition of combined extract beverage was plotted against its concentration. The half maximal inhibitory concentration $\left(\mathrm{IC}_{50}\right)$ was calculated by using the equation from its graph [21]. All determinations were performed in triplicate.

2.6. Determination of Ferric-Reducing Antioxidant Power (FRAP) Assay. The assessment of ferric-reducing antioxidant power (FRAP) was performed based on the ability of the tested substance to reduce ferric tripyridyl triazine (Fe III TPTZ) complex to ferrous form (intense blue color) at low $\mathrm{pH}$ by using a modified method of Benzie and Strin [22]. FRAP reagent was freshly prepared by mixing solution A (300 mM acetate buffer $\mathrm{pH} 3.6)$, solution B (10 mM 2,4,6- 
tripyridyl-striazine (TPTZ) in $40 \mathrm{mM} \mathrm{HCl}$ ), and solution $\mathrm{C}$ (20 mM ferric chloride) together at a ratio of $\mathrm{A}: \mathrm{B}: \mathrm{C}$; $10: 1: 1$, respectively, and kept in water bath at $37^{\circ} \mathrm{C}$. The tested substance $(50 \mu \mathrm{l})$ was added to FRAP reagent $(1.45 \mathrm{ml})$, mixed thoroughly, and incubated at $37^{\circ} \mathrm{C}$ for 10 minutes. The absorbance was measured with spectrophotometer at $593 \mathrm{~nm}$ (Pharmacia LKB-Biochrom4060). FRAP reagent and L-ascorbic acid $(100-1000 \mu \mathrm{M})$ were used as blank and standard calibration, respectively. Data were expressed as $\mu \mathrm{M}$ L-ascorbic acid equivalent.

2.7. Determination of Anthocyanin Content. Anthocyanin content was determined according to the official method of the Association of Official Analytical Chemists (AOAC) [23]. The tested sample $(1 \mathrm{ml})$ was mixed with $0.025 \mathrm{M}$ potassium chloride $\mathrm{pH} 1.0(2 \mathrm{ml})$ or $0.4 \mathrm{M}$ sodium acetate $\mathrm{pH} 4.5(2 \mathrm{ml})$. After the incubation at room temperature for 10 minutes, the absorbance was determined at 520 and $720 \mathrm{~nm}$ using a UV-spectrophotometer (Pharmacia LKB-Biochrom 4060). All assessments were performed as triplicate. Anthocyanin content was calculated and expressed as mg/l cyaniding-3-glucoside equivalent/mg extract (mg/l CGE) as follows:

$$
\begin{aligned}
& \text { Anthocyanin content }\left(\frac{\text { cyanindin }-3-\text { glucoside equivalent, mg }}{1}\right) \\
& =\frac{\left(\mathrm{A} \times \mathrm{MW} \times \mathrm{DF} \times 10^{3}\right)}{(\varepsilon \times 1)},
\end{aligned}
$$

where $A=(A 520 \mathrm{~nm}-\mathrm{A} 700 \mathrm{~nm})$ pH $1.0-(\mathrm{A} 520 \mathrm{~nm}-\mathrm{A}$ $700 \mathrm{~nm}$ ) pH4.5, MW (molecular weight) $=449.2 \mathrm{~g} / \mathrm{mol}$, $\mathrm{DF}=$ dilution factor obtained from the study, $\varepsilon=26,900$ molar extinction coefficient, in $1 \mathrm{~mol}^{-1} \mathrm{~cm}^{-1}$, for cyanindin3-glucoside, $10^{3}$ = factor for conversion from $\mathrm{g}$ to $\mathrm{mg}$, and $1=$ path length of the cuvette in $\mathrm{cm}(1 \mathrm{~cm})$.

2.8. Assessment of Acetylcholinesterase Inhibitory (AChEI) Activity. Inhibition of acetylcholinesterase of the sample was determined according to the method previously described [24] using acetylthiocholine chloride iodide (ATCI) as a substrate. In brief, combined extract beverage $(25 \mu \mathrm{l})$ was incubated with $15 \mathrm{mM}$ ATCI $(25 \mu \mathrm{l}), 3 \mathrm{mM}$ DTNB (5,5'-dithiobis[2-nitrobenzoic acid]) (75 $\mu \mathrm{l})$, and $50 \mathrm{mM}$ Tris buffer ( $\mathrm{pH} 8)(50 \mu \mathrm{l})$ for 5 minutes at room temperature. The absorbance was measured with a microplate reader (iMark ${ }^{\mathrm{TM}}$ Microplate Absorbance Reader) at $415 \mathrm{~nm}$ before and after adding 0.25 units $/ \mathrm{ml}$ acetylcholinesterase (AChE) $(25 \mu \mathrm{l})$ to the mixture. The elevation of yellow color from the reaction was obtained and the percentage inhibition was calculated by comparing the yellow color of extract to a noninhibition well (Tris buffer). All tests were conducted in triplicate.

2.9. Fingerprint Chromatogram Assessment. The fingerprint chromatogram of the developed drink was analyzed by using gradient high-performance liquid chromatography (HPLC) system. High-performance liquid chromatography (HPLC) system consisted of 515 HPLC pump and 2998 photodiode array detector (Water Company, USA). Chromatographic separation was performed using Purospher ${ }^{\circledR S T A R, ~ C-18 ~}$ endcapped $(5 \mu \mathrm{m})$, LiChroCART ${ }^{\circledR} 250-4.6$, and HPLCCartridge, sorbet lot number HX255346 (Merk, Germany) with guard column (Merk, Germany). Methanol (A) and $7.5 \%$ acetic acid in deionized (DI) water (B) were used as mobile phases. The gradient elution was carried out at a flow rate of $1.0 \mathrm{ml} / \mathrm{min}$ with the following gradient: $0-17 \mathrm{~min}$, 70\%A; $18-22 \mathrm{~min}, 100 \% \mathrm{~A} ; 23-25,50 \% \mathrm{~A}$; and $26-30 \mathrm{~min}$, $60 \% \mathrm{~A}$. The sample was filtered $(0.45 \mu \mathrm{m}$, Millipore), and a direct injection of tested sample at the volume of $20 \mu \mathrm{l}$ on the column was performed. The chromatograms were recorded at $280 \mathrm{~nm}$ using a UV detector and data analysis was performed using EmpowerTM3.

2.10. Experimental Animals and Protocols. Female Wistar rats (Laboratory Animal Center, Salaya, Nakhon Pathom, Thailand), weighing 200-250 g, were used as the experimental animals. They were randomly housed 6 per cage in a temperature-controlled room on a $12 \mathrm{~h}$ light/dark cycle with ad libitum access to food and water. All procedures in this experiment were strictly performed in accordance with the internationally accepted principles for laboratory use and care of the European Community (EEC directive of 1986; $86 / 609 /$ EEC). The experiment protocols were approved by the Institutional Animal Care and Unit Committee, Khon Kaen University, Thailand (record number AEKKU 1/2556).

The experimental rats were divided into 8 groups ( $n=6$ /group) as follows:

Group I: Naïve intact group; all rats received no treatment and were served as the control group.

Group II: Sham operation + vehicle; all rats were subjected to sham operation surgery and received distilled water which was served as the vehicle in this study.

Group III: OVX + vehicle; the experimental animals in this group were subjected to bilateral ovariectomy (OVX) and received the vehicle.

Group IV: OVX + donepezil (3 mg/kg BW); the OVX rats were orally given donepezil, an acetylcholinesterase inhibitor, at a dose of $3 \mathrm{mg} / \mathrm{kg}$ and were served as the positive controltreated group.

Group V: OVX + isoflavone; all OVX rats were orally given isoflavone, a well-known polyphenol substance with cognitive enhancing, at a dose of $20 \mathrm{mg} / \mathrm{kg}$ BW.

Groups VI-VIII: OVX + PCP20, OVX + PCP40, and OVX + PCP80; the OVX rats in these groups received PCP at doses of 20,40 , and $80 \mathrm{mg} / \mathrm{kg} \mathrm{BW}$, respectively.

The treatment programs of the assigned substances for rats in groups II-VIII were started since the first day after surgery and were maintained throughout a 28-day experimental period. All treatments were performed once daily in the morning with the total volume of $1.5 \mathrm{ml}$. The assessment of nonspatial memory was performed every 7 days throughout the study period while the determinations of oxidative stress markers including malondialdehyde (MDA), superoxide dismutase (SOD), catalase (CAT), glutathione peroxidase (GSH-Px), the activity of acetylcholinesterase (AChE), histology, and ERK1/2 expression in the prefrontal cortex were determined at the end of the study. 
2.11. Ovariectomized Surgery Procedure. The experimental animal was anesthetized with sodium thiopental at the dose of $60 \mathrm{mg} / \mathrm{kg}$ BW via intraperitoneal route prior to the ovariectomy. The ovariectomized (OVX) procedure was performed according to the method which had been previously described [25]. Briefly, the dorsolateral incisions were performed bilaterally, the ovarian blood vessels were tied off, and the ovaries were removed. Then, the skin was sutured and the rat was returned to their cage after postoperation care. Sham operation was carried out with the same procedures except that both the ovaries were kept intact.

2.12. Object Recognition Test. The object recognition test, the common test for evaluating nonspatial memory in rats, was used to assess the effect of PCP on nonspatial memory. This test was performed as previously described elsewhere with minor modification [26]. In brief, each rat was placed in an open field ( $80 \mathrm{~cm}$ long $\times 50 \mathrm{~cm}$ high $\times 60 \mathrm{~cm}$ wide) with two identical objects for 3 minutes (T1) and then was placed back to its home cage. Both objects should be placed in a symmetric position in the central line of the area. Then, the animal was orally given the assigned substance, and 30 minutes later, the second 3-minute trial was performed. In this session, one of the objects was replaced with the novel object which was totally different in shape and size at the same location. During the intertrial interval, the objects and open-field apparatus object were cleaned with $70 \%$ ethanol to avoid a confounding error induced by the influence of odor. The amount of time which the rat spent exploring each object was recorded and calculated as a novel object ratio (NOR) as the following equation:

$$
\mathrm{NOR}=\frac{\left(T_{\text {novel }}-T_{\text {familiar }}\right)}{\left(T_{\text {novel }}+T_{\text {familiar }}\right)},
$$

where $T_{\text {novel }}=$ time spent to explore the novel object and $T_{\text {familiar }}=$ time spent to explore the familiar object.

2.13. Histological Study. After perfusion, the brains were removed and fixed with $4 \%$ paraformaldehyde solution $(\mathrm{pH} 7.4)$ at $4^{\circ} \mathrm{C}$. Then, they were cryoprotected in formalinsucrose (30\%) for 2-3 days. Serial sections of tissue containing prefrontal cortex were cut frozen on a cryostat (Thermo Scientific ${ }^{\mathrm{TM}}$ HM 525 Cryostat) at $20 \mu \mathrm{m}$ thick and mounted on slides coated with $0.3 \%$ aqueous solution of gelatin containing $0.05 \%$ aluminum potassium sulfate. To stain with cresyl violet, the slides were air dried; hydrated by successive immersion in 95, 70, and 50\% ethanol; stained in $0.5 \%$ cresyl violet for $2 \mathrm{~min}$ at room temperature; dehydrated by successive immersion in 50,70, 95, and 100\% ethanol and xylene; and mounted with DPX. Three representative slides containing the prefrontal cortex were selected according to the stereotaxic coordinates anteroposterior $2.5-4.5 \mathrm{~mm}$ and mediolateral $0.2-1.0 \mathrm{~mm}$ from the rat brain atlas [27]. The analysis was performed by a blinded observer. The evaluation was performed via Olympus light microscope model $\mathrm{BH}-2$ (Japan) at 40x magnification. The density of survival neurons in medial prefrontal cortex area (mPFC) was expressed as number of cells $/ 255 \mu \mathrm{m}^{2}$.
2.14. Determination of Extracellular Signal-Regulated Kinase 1/2 (ERK1/2) Expression. The prefrontal cortex was subjected to a 2-minute homogenization in $1 / 10(w / v)$ M-PER mammalian protein extraction (Pierce Protein Biology Product, Rockford, IL, USA) containing protease inhibitor cocktail (Sigma-Aldrich). Then, it was centrifuged at $14,000 \mathrm{~g}$ for 10 minutes at $4^{\circ} \mathrm{C}$. The supernatant was harvested and used for the determination of ERK1/2 expression. Protein concentration of the supernatant was quantified by using NanoDrop instrument (Thermo Fisher Scientific, Wilmington, Delaware USA). Total $30 \mu \mathrm{g}$ of brain samples were separated by $10 \%$ sodium dodecyl sulfate polyacrylamide gel electrophoresis (SDS-PAGE) at $80 \mathrm{~V}$. All protein bands were transferred.

The determination of ERK1/2 protein was performed according to the method previously described with a minor modification [28]. Total of $30 \mu \mathrm{g}$ of brain samples were separated by $10 \%$ sodium dodecyl sulfate polyacrylamide gel electrophoresis (SDS-PAGE) at $80 \mathrm{~V}$. Proteins from the gel were transferred to a nitrocellulose membrane (Bio-Rad Laboratories) and blocked with 5\% nonfat dry milk in $0.1 \%$ tween 20 tris-buffered saline (TBS-T) for 30 minutes. After the blocking of a membrane, they were incubated with primary antibody which recognized ERK1/2 or monoclonal rabbit antiphosphorylated p44/p42 mitogen-activated protein kinase (MAPK) (Cell Signaling Technology Inc.; dilution, $1: 1000$ ) for 2 hours at room temperature. Then, they washed and incubated with secondary antibody conjugated with horseradish peroxidase or anti-rabbit IgG, HRPlinked antibody (Cell Signaling Technology Inc.; dilution, $1: 2000)$ for 2 hours at room temperature. The band density was detected with an enhanced chemiluminescent (ECL) system (GE Healthcare, Piscataway, NJ). The analysis was performed using ImageQuant TL analysis software (GE Healthcare, Piscataway, NJ). The expression was normalized using antitotal ERK1/2. Data were presented as a relative density to the naïve control.

2.15. Biochemical Assays. The prefrontal cortex, an important area in learning and memory, was isolated and prepared as brain homogenate by subjecting to homogenization with 50 volume of $0.1 \mathrm{M}$ phosphate buffer saline. Then, the homogenate was used for the determination of acetylcholinesterase (AChE) activity and oxidative stress status including malondialdehyde (MDA) level and the activities of superoxide dismutase (SOD), catalase (CAT), and glutathione peroxidase (GSH-Px). Protein concentration was assessed according to the Lowry method [29] and albumin bovine serum $(2-20 \mathrm{mg} / \mathrm{ml})$ was used as a standard.

The determination of AChE was carried out to reflect the cholinergic function in OVX rats by the colorimetric method [30]. A reaction mixture of $200 \mu \mathrm{l}$ of $0.1 \mathrm{mM}$ sodium phosphate buffer ( $\mathrm{pH} 8.0$ ), $10 \mu \mathrm{l}$ of $0.2 \mathrm{M}$ DTNB (5,5'-dithio-bis(2-nitrobenzoic acid)), and $20 \mu$ of the sample solution were incubated for 5 minutes, and the absorbance at $415 \mathrm{~nm}$ was recorded via microplate reader (iMark Microplate Absorbance Reader). Then, $10 \mu \mathrm{l}$ of acetylcholine thiochloride (ACTI) was added, incubated for 3 minutes, and recorded the absorbance at $415 \mathrm{~nm}$. The activity of AChE was 
calculated according to the equation below and expressed as $\mathrm{mmol} / \mathrm{min} / \mathrm{g}$ protein.

$$
\text { AChE activity }=\left(\Delta A / 1.36 \times 10^{4}\right) \times 1 /(20 / 230) C,
$$

where $\Delta A=$ the difference of absorbance/minute and $C=$ protein concentration of brain homogenate.

MDA level was assessed according to the method of Thiraphatthanavong et al. [31]. In brief, the mixture of $0.1 \mathrm{ml}$ of brain homogenate, $0.1 \mathrm{ml}$ of $8.1 \%(w / v)$ sodium dodecyl sulfate, $0.75 \mathrm{ml}$ of $20 \%(v / v)$ acetic acid $\mathrm{pH} 3.5$, $0.75 \mathrm{ml}$ of $0.8 \%(w / v)$ thiobarbituric acid, and $0.3 \mathrm{ml}$ of distilled water were mixed thoroughly and boiled at $95^{\circ} \mathrm{C}$ for 1 hour. After cooling, $0.5 \mathrm{ml}$ of water and $2.5 \mathrm{ml}$ of the mixture of $n$-butanol and pyridine at the ratio of $15: 1$ were added, mixed together, and centrifuged at $4000 \mathrm{rpm}$ for 10 minutes. The pink layer was harvested and determined the optical density at $532 \mathrm{~nm}$. 1,1,3,3-tetramethoxypropane $(2-20 \mathrm{nmol})$ was served as a standard and MDA level was expressed as $\mathrm{nmol} / \mathrm{mg}$ protein.

SOD assessment was performed according to the method previously described elsewhere [32]. Briefly, $20 \mu \mathrm{l}$ of brain homogenate was mixed with the mixture which contained $216 \mathrm{mM}$ potassium phosphate buffer $\left(\mathrm{KH}_{2} \mathrm{PO}_{4}\right), 10.7 \mathrm{mM}$ ethylenediaminetetraacetic acid, $1.1 \mathrm{mM}$ cytochrome C, and $0.54 \mathrm{mM}$ xanthine solution $\mathrm{pH} 7.4$ at the ratio of $25: 1: 1: 50$. Then, $20 \mu \mathrm{l}$ of $0.05 \mathrm{units} / \mathrm{ml}$ of xanthine oxidase was added and incubated for 5 minutes at room temperature. The absorbance was measured at $490 \mathrm{~nm}$ using microplate reader. SOD enzyme activities at the concentrations of $0-10 \mathrm{units} / \mathrm{ml}$ were used as standards, and the results were expressed as units/mg protein.

The activity of catalase (CAT) was evaluated indirectly by measuring the residual $\mathrm{H}_{2} \mathrm{O}_{2}$ which was titrated by potassium permanganate. In brief, $10 \mu \mathrm{l}$ of brain homogenate was mixed with $50 \mu \mathrm{l}$ of $30 \mathrm{mM} \mathrm{H}_{2} \mathrm{O}_{2}, 25 \mu \mathrm{l}$ of $5 \mathrm{~N}$ $\mathrm{H}_{2} \mathrm{SO}_{4}$, and $150 \mu \mathrm{l}$ of $5 \mathrm{mM} \mathrm{KMnO}_{4}$. The mixture was shaken and the absorbance was measured at $490 \mathrm{~nm}$. CAT enzyme at the concentration range of $0-10$ units $/ \mathrm{ml}$ was used as a standard and the result was expressed as units/mg protein [32].

Glutathione peroxidase activity was assessed using the colorimetric method. In brief, $10 \mu \mathrm{l}$ of brain homogenate was mixed with the mixture containing $50 \mu \mathrm{l}$ of $30 \mathrm{mM}$ $\mathrm{H}_{2} \mathrm{O}_{2}, 25 \mu \mathrm{l}$ of $5 \mathrm{~N} \mathrm{H}_{2} \mathrm{SO}_{4}$, and $150 \mu \mathrm{l}$ of $5 \mathrm{mM} \mathrm{KMnO}_{4}$. The mixture was shaken and the absorbance was measured at $490 \mathrm{~nm}$. The standard calibration curve was prepared by using CAT enzyme at the concentration range of $0-10$ units $/ \mathrm{ml}$. CAT activity was expressed as units/mg protein [32].

2.16. Statistical Analysis. Data are presented as mean \pm standard error of mean (SEM). The statistical analysis of the experiment was carried out using IBM SPSS Statistics (version 21). Data was analyzed using one-way analysis of variance (ANOVA), followed by Tukey's post hoc test. Probability levels less than 0.05 were accepted as significant.
TABLE 1: The biological activity of PCP including total phenolic compound, anthocyanin content, DPPH radical activity, FRAP activity, and AChEI activity.

\begin{tabular}{|c|c|c|}
\hline Test & РCP & $\begin{array}{l}\text { Standard } \\
\text { reference }\end{array}$ \\
\hline $\begin{array}{l}\text { Total phenolic compound } \\
\text { (mg/l GAE) }\end{array}$ & $184 \pm 1.91$ & - \\
\hline $\begin{array}{l}\text { Anthocyanin content } \\
(\mathrm{mg} / \mathrm{l} \mathrm{CGE})\end{array}$ & $25.66 \pm 0.32$ & - \\
\hline $\begin{array}{l}\text { FRAP activity } \\
\text { ( } \mu \mathrm{M} \text { L-ascorbic acid equivalent) }\end{array}$ & $602.40 \pm 2.33$ & - \\
\hline $\begin{array}{l}\text { DPPH radical activity } \\
\left(\mathrm{IC}_{50} \mu \mathrm{g} / \mathrm{ml}\right)\end{array}$ & $56.37 \pm 0.45$ & $\begin{array}{c}\text { Ascorbic acid } \\
2.89 \pm 0.01\end{array}$ \\
\hline $\begin{array}{l}\text { AChEI activity } \\
\left(\mathrm{IC}_{50} \mu \mathrm{g} / \mathrm{ml}\right)\end{array}$ & $1950 \pm 16.02$ & $\begin{array}{l}\text { Donepezil } \\
0.51 \pm 0.03 \\
\end{array}$ \\
\hline
\end{tabular}

\section{Results}

3.1. Biological Activities of the Combined Extract. Total phenolic compounds and anthocyanin content together with the biological activities including the antioxidant activity (DPPH and FRAP assay) and acetylcholinesterase inhibition activity of the combined extract were evaluated. The results showed that $1 \mathrm{ml}$ of the combined extract contained the total phenolic compounds and anthocyanin contents of $184.00 \pm 1.91 \mathrm{mg} / \mathrm{l}$ gallic acid equivalent and $25.66 \pm$ $0.32 \mathrm{mg} / \mathrm{l}$ cyanidin-3-glucoside equivalent, respectively. $\mathrm{IC}_{50}$ of the antioxidant activity via 2,2-diphenyl-1-picrylhydrazyl (DPPH) assay was $56.37 \pm 0.45 \mu \mathrm{g} / \mathrm{ml}$, whereas the antioxidant activity via ferric-reducing antioxidant power (FRAP) assay was $602.40 \pm 2.33 \mu \mathrm{M}$ L-ascorbic acid equivalent. In addition, AChEI activity showed $\mathrm{IC}_{50}$ at a concentration of $1950 \pm 16.02 \mu \mathrm{g} / \mathrm{ml}$ as shown in Table 1 .

3.2. The Fingerprint of the Combined Extract. Figure 1 shows the fingerprint chromatogram of PCP, the combined extract of purple corn cob and pandan leaves. More than 7 different peaks were observed in the chromatogram. Four of them were anthocyanins (peak 2-peak 5) including cyaniding-3glucoside (peak 2), pelargonidin-3-glucoside (peak 3), cyanidin 3-O-( $6^{\prime \prime}$-malonyl-glucoside) (peak 4$)$, and cyaniding-3-oB-glucopyranoside (peak 5). It was found that the contents of anthocyanins mentioned earlier in PCP were $3.239 \pm 0.014$, $2.543 \pm 0.011,2.993 \pm 0.024$, and $2.335 \pm 0.006 \mathrm{mg} / \mathrm{ml}$, respectively. In addition to anthocyanins, gallic acid, rutin, and ferulic acid were observed at the concentrations of $0.180 \pm$ $0.001,0.337 \pm 0.001$, and $0.341 \pm 0.027 \mathrm{mg} / \mathrm{ml}$, respectively.

\subsection{Effect of the Combined Extract on Nonspatial Memory in} OVX Rats. Memory-enhancing effect of the combined extract on nonspatial memory was shown in Figure 2. It was found that sham operation rats showed no significant change on novel object ratio (NOR). OVX rats treated with vehicle significantly decreased NOR throughout the study period ( $p$ value $<0.01,0.01,0.05$, and 0.05 , resp., compared with the sham operation group). OVX rats with isoflavone treatment attenuated the reduction of NOR induced by OVX throughout the study period ( $p$ value $<0.01,0.05,0.01$, and 


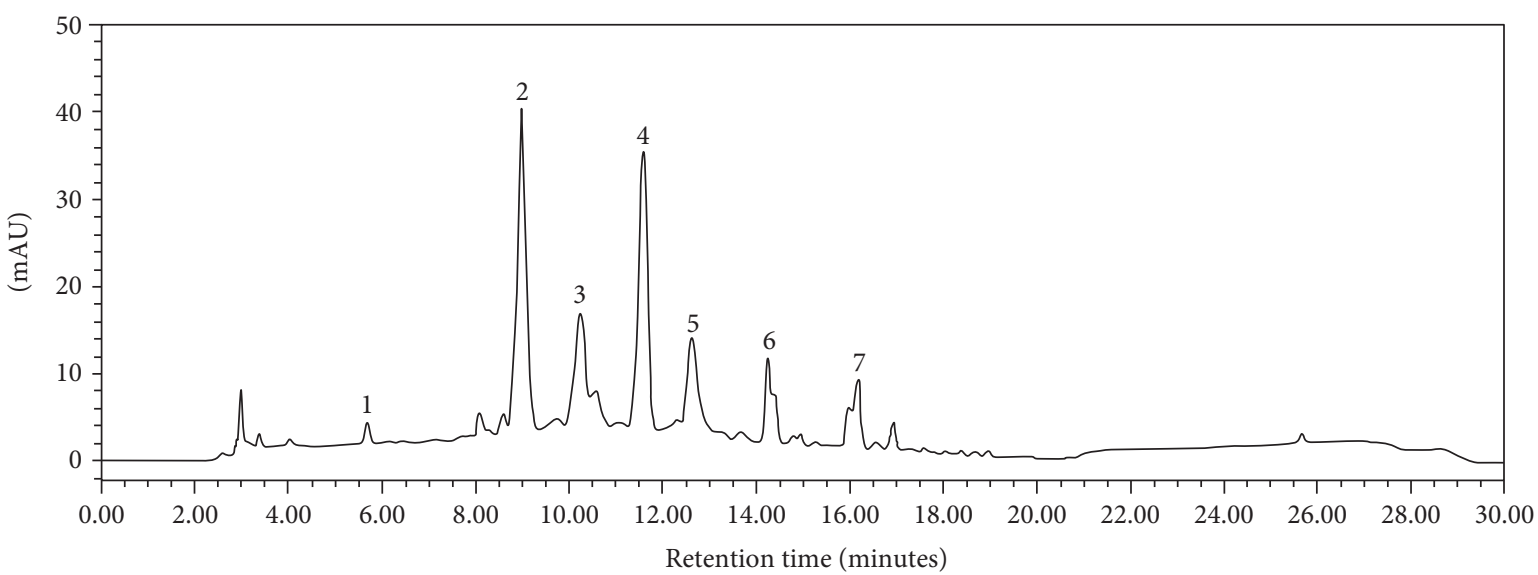

FIgure 1: The fingerprint chromatogram of the PCP using HPLC analysis.

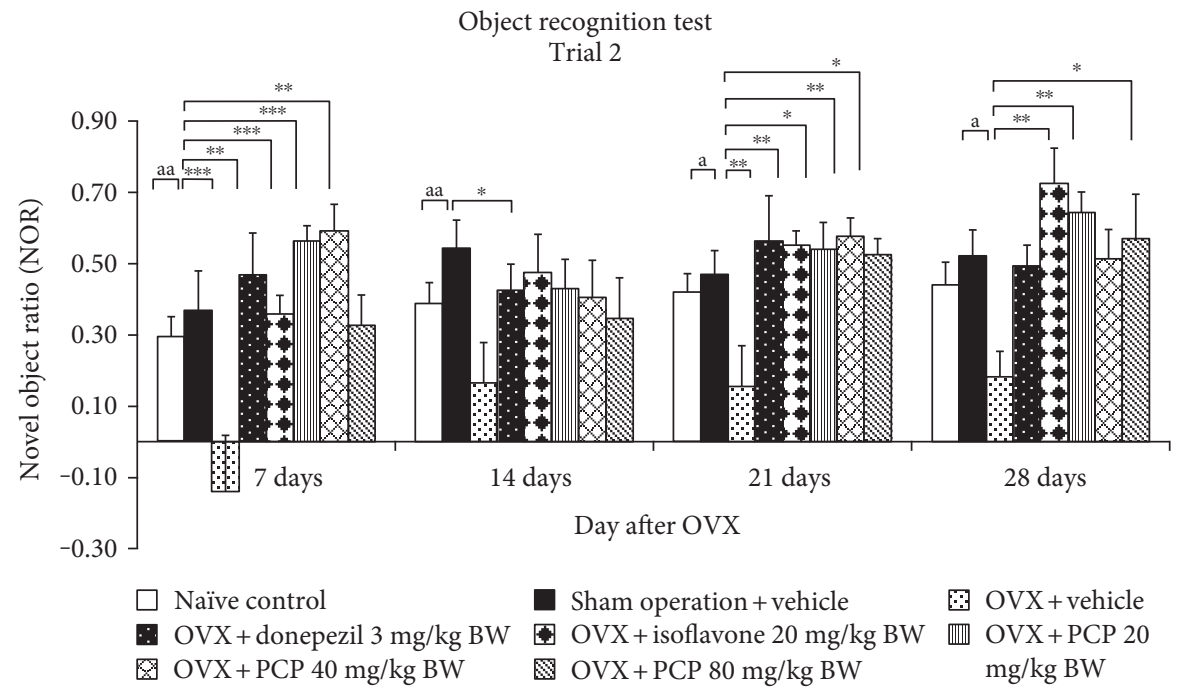

FIGURE 2: The effect of the PCP on nonspatial memory assessing by the object recognition test ( $n=6 /$ group). Data were expressed as mean \pm SEM. ${ }^{\text {a, aa }} p$ value $<0.05,0.01$, respectively, compared with the sham operation group. ${ }^{*},{ }^{* *},{ }^{* * *} p$ value $<0.05,0.01$, and 0.001 , respectively, compared with the OVX + vehicle-treated group.

0.01, resp., compared with OVX + vehicle). Donepezil also showed the mitigation effect on the reduction of NOR in OVX rats, but significant differences were observed only at 7 - and 21-day treatment periods ( $p$ value $<0.001$ and 0.01 , resp., compared with the OVX + vehicle-treated group). The combined extract at doses of 20 and $80 \mathrm{mg} / \mathrm{kg}$ BW significantly attenuated the decreased NOR in OVX rats at 7, 21, and 28 days of treatment ( $p$ value $<0.001$ and $0.01 ; 0.05$ all; and 0.01 and 0.05 , resp., compared with the OVX + vehicletreated group). The significant mitigation effect of PCP at a dose of $40 \mathrm{mg} / \mathrm{kg} \mathrm{BW}$ on NOR was also observed at 7 and 21 days of treatment ( $p$ value $<0.001$ and 0.01 , resp., compared with the OVX + vehicle-treated group). The increased NOR in the PCP treatment groups were also observed at a 14-day study period, but no significant difference was revealed.

3.4. Histological Change in the Prefrontal Cortex. Based on the previous finding that the prefrontal cortex played a crucial role on working memory in rodents [33], we also investigated the neuron density in this area and results were shown in Figure 3. The current results demonstrated that OVX treated with vehicle significantly reduced the neuron density in PFC ( $p$ value $<0.05$, compared with the sham operation group). Both donepezil and isoflavone could attenuate the reduction of neuron density in PFC of OVX rats $(p$ value $<0.01$ all; compared with the OVX + vehicle-treated group). In addition, combined extract at the dosage range used in this study also significantly attenuated the reduction of neuron density in PFC of OVX rats ( $p$ value $<0.01,0.01$, and 0.05 ; compared with the OVX + vehicle-treated group).

3.5. Biochemical Assays. Table 2 shows the effect of PCP on oxidative stress markers including MDA level and the activities of SOD, CAT, and GSH-Px. Sham operation showed no significant changes of the mentioned parameters. OVX rats which received vehicle significantly increased MDA level ( $p$ value $<0.05$; compared to the sham operation group) in the prefrontal cortex (PFC). Donepezil treatment 


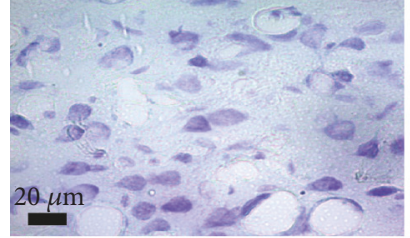

(a)

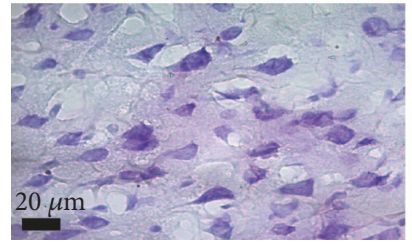

(e)

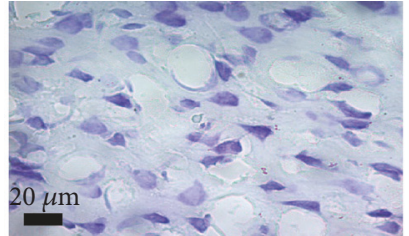

(b)

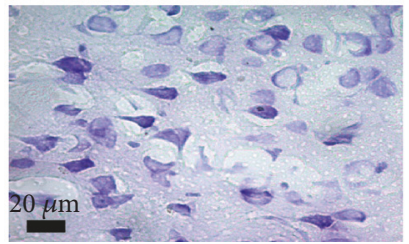

(f)

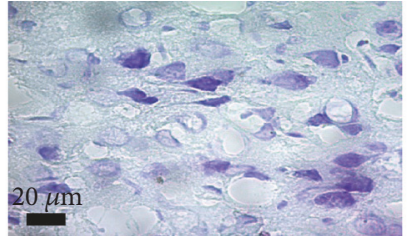

(c)

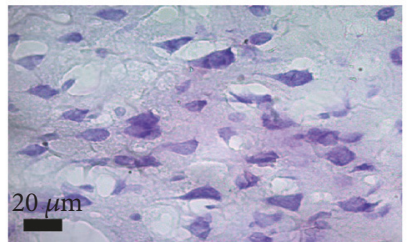

(g)

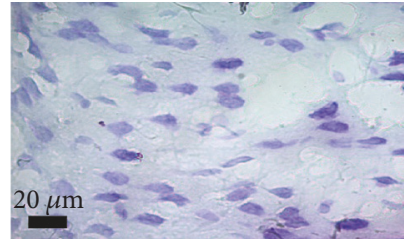

(d)

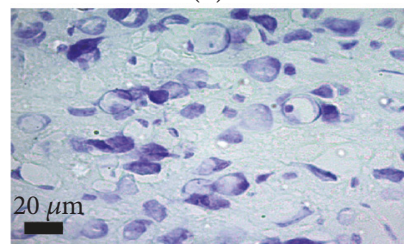

(h)

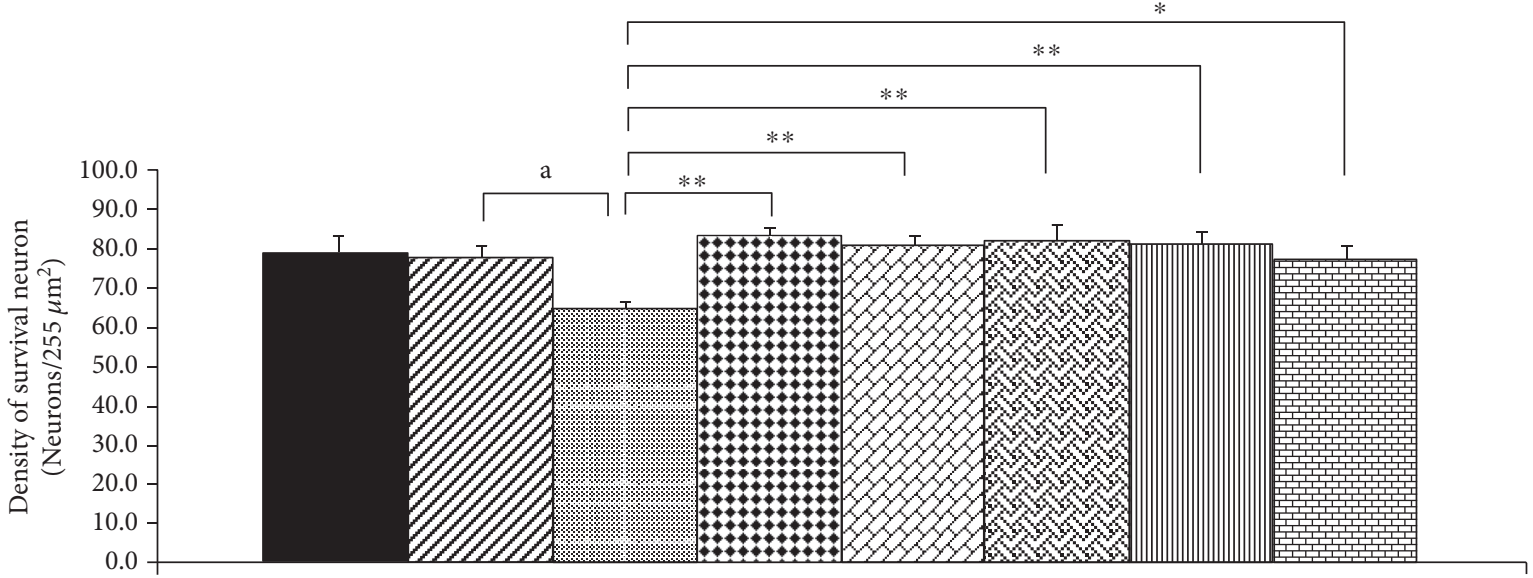

Prefrontal cortex

Naïve control

OVX + donepezil $3 \mathrm{mg} / \mathrm{kg} \mathrm{BW}$

III $\mathrm{OVX}+\mathrm{PCP} 40 \mathrm{mg} / \mathrm{kg} \mathrm{BW}$

OVX + vehicle
1. Sham operation + vehicle

OVX + isoflavone $20 \mathrm{mg} / \mathrm{kg}$ BW

OVX + PCP $80 \mathrm{mg} / \mathrm{kg} \mathrm{BW}$

OVX + PCP $20 \mathrm{mg} / \mathrm{kg} \mathrm{BW}$

Figure 3: The effect of the PCP on the density of survival neurons in medial prefrontal cortex (mPFC) ( $n=6 /$ group). The upper panel showed the photomicrograph of the coronal section of rat brains in (a) naïve control, (b) sham operation + vehicle, (c) OVX + vehicle, (d) OVX + donepezil, (e) OVX + isoflavone, (f) OVX + PCP $20 \mathrm{mg} / \mathrm{kg} \mathrm{BW,} \mathrm{(g)} \mathrm{OVX} \mathrm{+} \mathrm{PCP} 40 \mathrm{mg} / \mathrm{kg}$ BW, and (h) OVX + PCP $80 \mathrm{mg} / \mathrm{kg} \mathrm{BW}$. Scale bar: $20 \mu \mathrm{m}$. The lower panel demonstrated the density of survival neurons of mPFC. ${ }^{a} p$ value $<0.05$, compared with the sham operation group. ${ }^{*},{ }^{* *} p$ value $<0.05$ and 0.01 , respectively, compared with the OVX + vehicle-treated group. Data were expressed as mean \pm SEM.

failed to produce the significant changes on all parameters just mentioned in OVX rats. However, isoflavone significantly decreased MDA level but enhanced SOD activity ( $p$ value $<0.05$ and 0.01 , resp., compared to the OVX + vehicle-treated group). Interestingly, PCP at all doses used in this study significantly decreased MDA level in PFC ( $p$ value $<0.001$ all; compared to the OVX + vehicle-treated group). The elevation of SOD activity in PFC was observed in OVX rats which received PCP at the concentrations of 20 and $40 \mathrm{mg} / \mathrm{kg} \mathrm{BW}$ ( $p$ value $<0.001$ and 0.01 , resp., compared with the OVX + vehicle-treated group).

Since the cholinergic system plays a crucial role on learning and memory [34], we also investigated the effect of PCP on the cholinergic system by using the suppression activity of AChE or AChEI activity as an indirect index, and results were shown in Figure 4. It was found that both sham operation and OVX rats which received vehicle failed to produce the significant changes of AChE. The decreased AChE activity was observed in OVX rats which received donepezil and combined extract at the dose of $20 \mathrm{mg} / \mathrm{kg} \mathrm{BW}$ ( $p$ value $<0.05$ and 0.01 , resp., compared with the OVX rats + vehicletreated group). When compared with OVX rats which received vehicle, no significant changes of AChE were observed in the other groups.

3.6. ERK1/2 Signaling Pathway. Based on the crucial role of ERK1/2 on the survival neurons and memory enhancement [28], the effect of PCP on the phosphorylation ERK1/2 
TABLE 2: The effect of PCP on oxidative stress markers in the prefrontal cortex ( $n=6$ /group).

\begin{tabular}{|c|c|c|c|c|}
\hline \multirow[b]{2}{*}{ Treatment } & \multicolumn{4}{|c|}{ Oxidative stress markers in the prefrontal cortex } \\
\hline & $\begin{array}{c}\text { MDA } \\
\text { (nmol/mg protein) }\end{array}$ & $\begin{array}{c}\text { GSH-Px } \\
\text { (Units/mg protein) }\end{array}$ & $\begin{array}{c}\text { SOD } \\
\text { (Units/mg protein) }\end{array}$ & $\begin{array}{c}\text { CAT } \\
\text { (Units/mg protein) }\end{array}$ \\
\hline Naïve control & $0.073 \pm 0.0 .001$ & $0.661 \pm 0.034$ & $0.567 \pm 0.164$ & $2.707 \pm 0.234$ \\
\hline Sham operation & $0.077 \pm 0.007$ & $0.576 \pm 0.052$ & $0.834 \pm 0.256$ & $2.516 \pm 0.237$ \\
\hline OVX + vehicle & $0.095 \pm 0.008^{\mathrm{a}}$ & $0.523 \pm 0.034$ & $0.309 \pm 0.100$ & $2.684 \pm 0.216$ \\
\hline OVX + donepezil 3 mg/kg BW & $0.090 \pm 0.007$ & $0.714 \pm 0.047$ & $1.387 \pm 0.344$ & $2.650 \pm 0.187$ \\
\hline OVX + isoflavone $20 \mathrm{mg} / \mathrm{kg} \mathrm{BW}$ & $0.059 \pm 0.005^{*}$ & $0.902 \pm 0.111$ & $2.220 \pm 0.458^{* *}$ & $2.130 \pm 0.210$ \\
\hline $\mathrm{OVX}+\mathrm{PCP} 20 \mathrm{mg} / \mathrm{kg} \mathrm{BW}$ & $0.047 \pm 0.012^{* * *}$ & $0.866 \pm 0.186$ & $3.080 \pm 0.352^{* * *}$ & $2.447 \pm 0.359$ \\
\hline $\mathrm{OVX}+\mathrm{PCP} 40 \mathrm{mg} / \mathrm{kg} \mathrm{BW}$ & $0.034 \pm 0.002^{* * *}$ & $0.799 \pm 0.070$ & $2.047 \pm 0.184^{* *}$ & $2.151 \pm 0.160$ \\
\hline $\mathrm{OVX}+\mathrm{PCP} 80 \mathrm{mg} / \mathrm{kg} \mathrm{BW}$ & $0.032 \pm 0.004^{* * *}$ & $0.639 \pm 0.029$ & $1.068 \pm 0.366$ & $1.921 \pm 0.092$ \\
\hline
\end{tabular}

${ }^{a} p$ value $<0.05$, compared with the sham operation group. ${ }^{*},{ }^{* *},{ }^{* * *} p$ value $<0.05,0.01$, and 0.001 , respectively, compared with the OVX + vehicle-treated group. Data were expressed as mean \pm SEM.

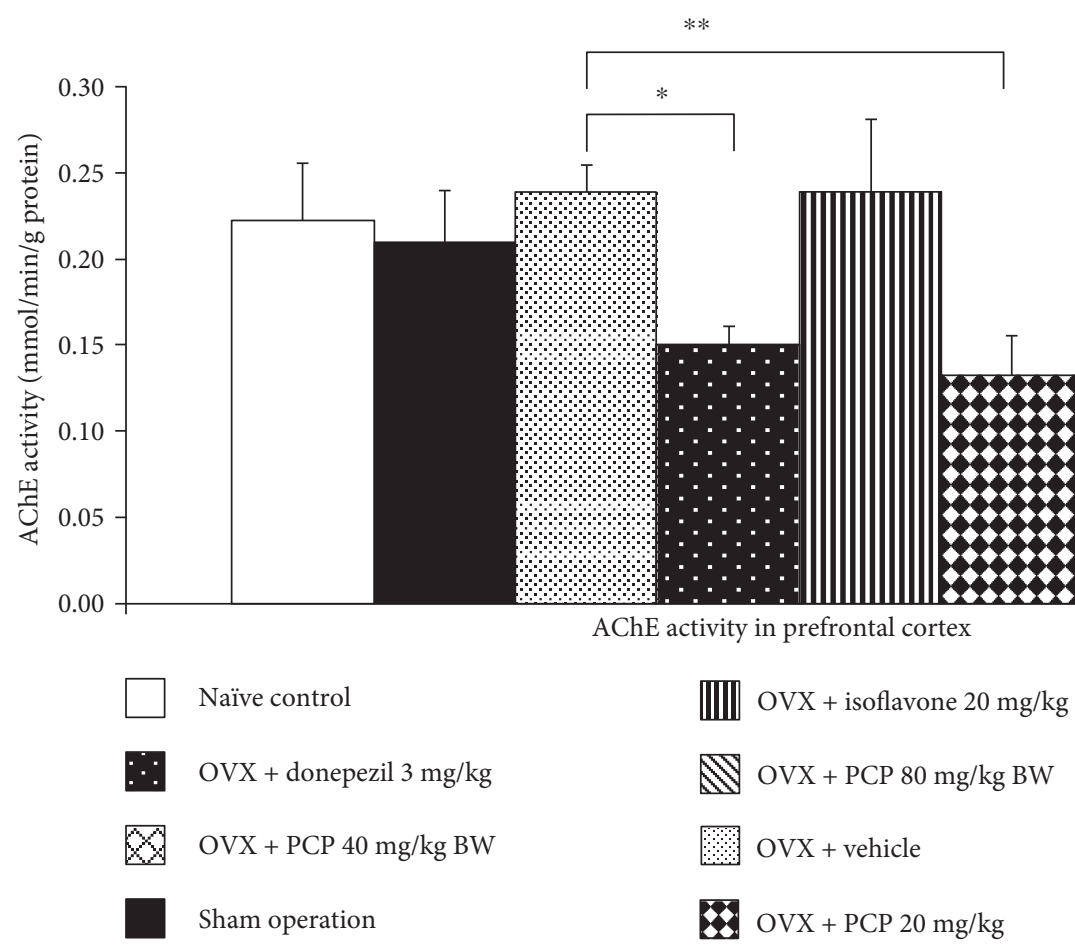

FIGURE 4: The effect of PCP on the activity of AChE in the prefrontal cortex $(n=6 /$ group $) .{ }^{*},{ }^{* *} p$ value $<0.05$ and 0.01 , respectively, compared with the OVX + vehicle-treated group. Data were expressed as mean \pm SEM.

was also determined, and results were shown in Figure 5. The current data showed that OVX rats significantly decreased expression of phosphorylation ERK1/2 in PFC ( $p$ value $<0.001$; compared with the sham operation group). Isoflavone and medium dose of PCP produced the significant attenuation effect induced by $\operatorname{OVX}$ ( $p$ value $<0.01$ and 0.05 , resp., compared with the OVX + vehicle-treated group).

\section{Discussion}

The current data showed that ovariectomy, a widely used model of menopause, increased oxidative stress status, impairment of the cholinergic system, and memory impairment which were in concordance with the previous study $[35,36]$. In the present study, it was found that OVX increased MDA without changes of the main scavenger enzymes such as SOD, CAT, and GSH-Px. This was in agreement with the previous study [37]. These results suggested that the elevation of MDA level might occur either via the increased oxidative stress production or via the decreased function of the nonenzymatic antioxidant system. Interestingly, PCP, the combined extract of purple corn cob and pandan leaves attenuated the memory impairment evaluated by using the object recognition test. 

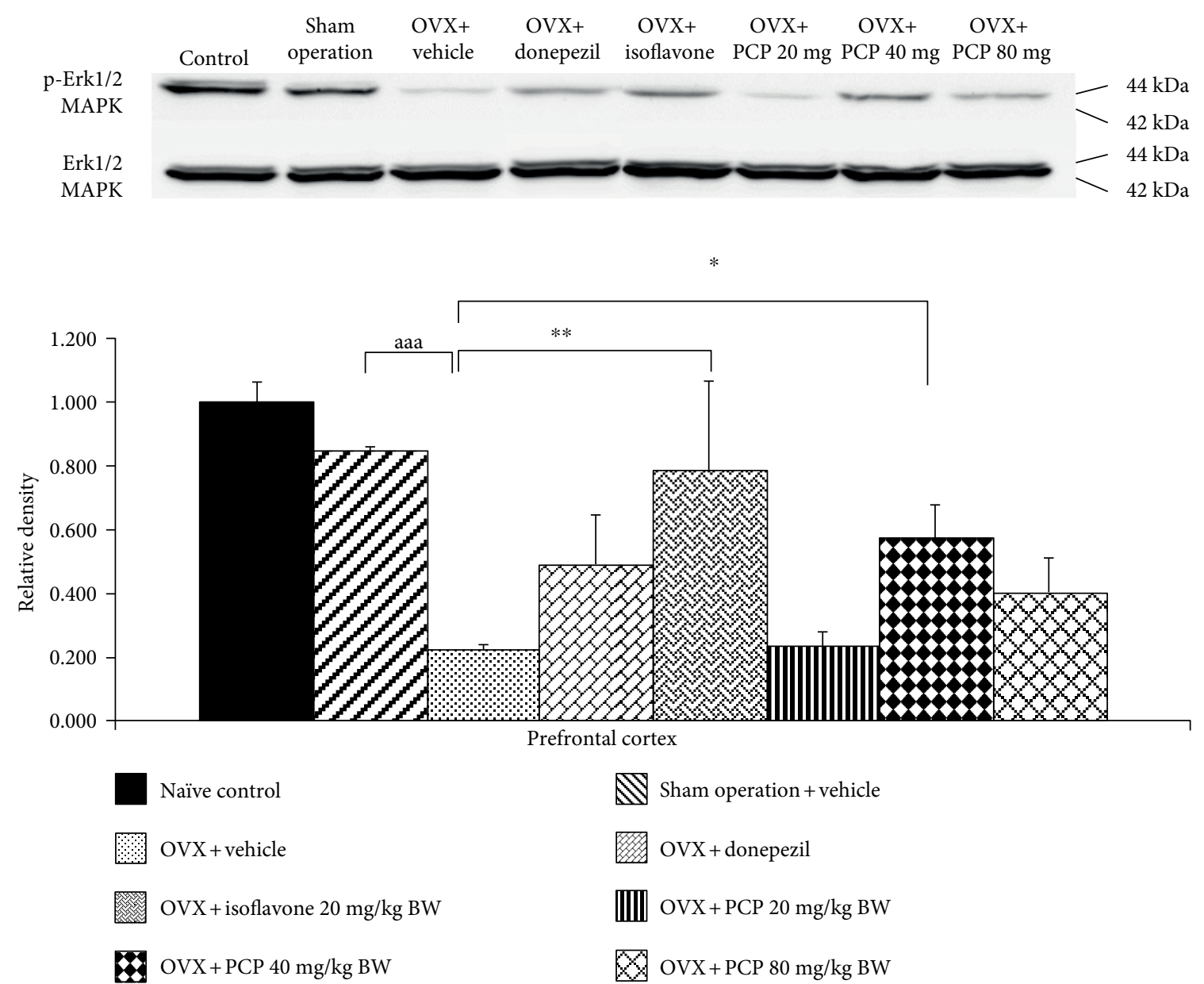

FIGURE 5: The effect of the PCP on the expression of phosphorylation ERK1/2 (p-ERK1/2) protein in the prefrontal cortex $\left(n=6 /\right.$ group). ${ }^{\text {aaa }} p$ value $<0.001$, compared with the sham operation group. ${ }^{*},{ }^{* *} p$ value $<0.05$ and 0.01 , respectively, compared with the OVX + vehicle-treated group. Data were expressed as mean \pm SEM.

It has been reported that the prefrontal cortex plays a crucial role on nonspatial memory. Lesion of this area could induce nonspatial memory impairment [38]. In this study, we have found that this impairment was attenuated by both isoflavone and all doses of PCP. The reduction of MDA level which indicated the decreased oxidative stress status and the enhanced neuron density was also observed in OVX rats which received isoflavone and all doses of PCP. Therefore, we suggested that PCP and isoflavone might improve oxidative stress status leading to the enhanced neuron density in PFC resulting in the improved nonspatial memory. The decreased oxidative stress status in PFC observed in this study might occur partly via the enhanced function of a scavenger enzyme especially SOD. Since no closed relationship between the decreased MDA level and the enhanced SOD activity in PFC was observed, other factors such as the decreased nonenzymatic system and the decreased oxidative stress production mentioned earlier might also contribute to the role.

In addition to oxidative stress, the cholinergic system in PFC also plays the crucial role on memory. Depletion of acetylcholine (ACh) together with the elevation of acetylcholinesterase (AChE) in the PFC induces memory impairment both in primates and in rodents [39, 40]. The cognitive-enhancing effect of donepezil, an AChEI, was observed without changes of oxidative stress markers. Our study also demonstrated that both donepezil and low dose of PCP also suppressed AChE activity in PFC. Therefore, the enhanced cholinergic function in PFC by suppressing AChE activity in the mentioned area also contributes to a role on the cognitive-enhancing effect of both substances. It has been reported that polyphenol [14] including anthocyanins [41] can improve memory impairment induced by scopolamine which exerts the effect at muscarinic receptors. Since PCP contains polyphenols and anthocyanins, it is also possible that PCP also exerts its influence on muscarinic receptor. However, this requires further investigation.

Recently, it has been demonstrated that mitogenactivated protein kinase (MAPK) especially ERK1/2 contributes to the pivotal role on learning and memory [42]. The substances which improve ERK signaling also improve the impairment of object recognition memory [43]. Based on this information, we did suggest that the cognitive-enhancing effect of isoflavone and medium dose of PCP might also occur via the enhanced ERK1/2 signaling pathway. 
Anthocyanins, a member of flavonoids, have been shown to exert the neuroprotective and cognitive-enhancing effect [44]. Since our fingerprint of PCP showed that the main ingredient in PCP was anthocyanins (peak 2-peak 5), we suggested that the neuroprotective effect and cognitiveenhancing effects of PCP in this study might involve anthocyanins. However, the effect of other ingredients still cannot be omitted.

Our data failed to show a dose-dependent manner of PCP. The possible explanation might be due to the nonsimple linear relationship between the concentration of PCP and the observed parameters. Since many factors exert the influences on the observed parameters in this study, no simple linear relationship was observed. In addition, PCP contained many ingredients, so the effect of an active ingredient could be masked by other ingredients.

In this study, we have found that our data showed that although in vitro data showed that $\mathrm{IC}_{50}$ of AChEI of PCP was very high, low dose of PCP could exert the cognitiveenhancing effect via the suppression of AChE in the prefrontal cortex while the medium and high doses of PCP failed to exert this effect. The possible explanation might also occur as that mentioned earlier in the lack of a dose-dependent study.

Taken all data together, our study highlights the neuroprotective and cognitive effects of PCP that might occur primarily via the decreased oxidative stress which in turn increased neuron density in the brain especially in PFC, an area playing an important role on learning and memory especially nonspatial memory, resulting in the improved nonspatial memory. However, the improved cholinergic function and signal transduction via ERK1/2 might also exert the roles especially at low and medium doses, respectively.

\section{Conclusion}

This study is the first study to demonstrate the neuroprotective and cognitive effects of PCP. We have shown that the combined extract of purple corn cob and pandan leaves can be served as functional ingredients for developing neuroprotectant and cognitive enhancer for menopausal women. Therefore, we highlight how to create the value for agricultural waste such as purple corn cob. However, chronic toxicity is required in order to assure the consumption safety before moving forward to a clinical trial study.

\section{Conflicts of Interest}

The authors declare that they have no conflicts of interest.

\section{Acknowledgments}

This study was supported by the Higher Education Research Promotion and National Research University Project of Thailand, Office of the Higher Education Commission, through the Food and Functional Food Research Cluster of Khon Kaen University, the Integrative Complementary Alternative Medicine Research and Development Center, and the Invitation Research Grant of the Faculty of Medicine (Grant no. IN58219), Khon Kaen University.

\section{References}

[1] World Health Organization, WHO Technical Report Series 866: Research on the Menopause in the 1990s, WHO Library Cataloguing in Publication Data, Geneva, Switzerland, 1994.

[2] J. R. Sliwinski, A. K. Johnson, and G. R. Elkins, "Memory decline in peri- and post-menopausal women: the potential of mind-body medicine to improve cognitive performance," Integrative Medicine Insights, vol. 9, pp. 17-23, 2014.

[3] E. Hogervorst, J. Williams, M. Budge, W. Riedel, and J. Jolles, "The nature of the effect of female gonadal hormone replacement therapy on cognitive function in post-menopausal women: a meta-analysis," Neuroscience, vol. 101, no. 3, pp. 485-512, 2000.

[4] M. Sano, "Understanding the role of estrogen on cognition and dementia," Journal of Neural Transmission Supplementum, vol. 59, pp. 233-239, 2000.

[5] S. A. Shumaker, C. Legault, L. Kuller et al., "Conjugated equine estrogens and incidence of probable dementia and mild cognitive impairment in postmenopausal women: Women's Health Initiative Memory Study," The Journal of the American Medical Association, vol. 291, no. 24, pp. 2947-2958, 2004.

[6] M. A. Espeland, S. R. Rapp, S. A. Shumaker; et al., "Conjugated equine estrogens and global cognitive function in postmenopausal women: Women's Health Initiative Memory Study," The Journal of the American Medical Association, vol. 291, no. 24, pp. 2959-2968, 2004.

[7] S. M. Resnick, P. M. Maki, S. R. Rapp et al., "Effects of combination estrogen plus progestin hormone treatment on cognition and affect," The Journal of Clinical Endocrinology and Metabolism, vol. 91, no. 5, pp. 1802-1810, 2006.

[8] V. Beral, "Breast cancer and hormone-replacement therapy in the Million Women Study," Lancet, vol. 362, no. 9382, pp. 419-427, 2003.

[9] W. Y. Chen, S. E. Hankinson, S. J. Schnitt, B. A. Rosner, M. D. Holmes, and G. A. Colditz, "Association of hormone replacement therapy to estrogen and progesterone receptor status in invasive breast carcinoma," Cancer, vol. 101, no. 7, pp. 1490-1500, 2003.

[10] O. H. Franco, R. Chowdhury, J. Troup et al., "Use of plantbased therapies and menopausal symptoms: a systematic review and meta-analysis," Journal of the American Medical Association, vol. 315, no. 23, pp. 2554-2563, 2016.

[11] P. Leerasiri, C. Chayachinda, S. Indhavivadhana, T. Wongwananurak, C. Dangrat, and M. Rattanachaiyanont, "Nutritional supplements in health-conscious pre-/postmenopausal Thai women," Journal of the Medical Association of Thailand, vol. 93, no. 10, pp. 1128-1136, 2010.

[12] C. W. Cotman, E. Head, B. A. Muggenburg, S. Zicker, and N. W. Milgram, "Brain aging in the canine: a diet enriched in antioxidants reduces cognitive dysfunction," Neurobiology of Aging, vol. 23, no. 5, pp. 809-818, 2002.

[13] J. Rubio, W. Qiong, X. Liu et al., "Aqueous extract of black maca (Lepidium meyenii) on memory impairment induced by ovariectomy in mice," Evidence-Based Complementary and Alternative Medicine, vol. 2011, Article ID 253958, 7 pages, 2011.

[14] Y. S. Juan, S. M. Chuang, Y. L. Lee et al., "Green tea catechins decrease oxidative stress in surgical menopause-induced overactive bladder in a rat model," BJU International, vol. 110, no. 6, Part B, pp. E236-E244, 2012. 
[15] G. Patki, F. H. Allam, F. Atrooz et al., "Grape powder intake prevents ovariectomy-induced anxiety-like behavior, memory impairment and high blood pressure in female Wistar rats," PloS One, vol. 8, no. 9, article e74522, 2013.

[16] F. Ramos-Escudero, A. M. Muñoz, C. Alvarado-Ortíz, Á. Alvarado, and J. A. Yáñez, "Purple corn (Zea mays L.) phenolic compounds profile and its assessment as an agent against oxidative stress in isolated mouse organs," Journal of Medicinal Food, vol. 15, no. 2, pp. 206-215, 2012.

[17] R. Chaisanam, S. Muchimapura, J. Wattanathorn, W. Thukham-mee, and J. Jittiwat, "Antioxidant and cyclooxygenase-2-inhibiting effect of purple corn cob extract-loaded nanofiber patch on motor recovery in spinal cord injury rats," North-Eastern Thai Journal of Neuroscience, vol. 10, no. 4, pp. 14-33, 2015.

[18] S. W. Yan and R. Asmah, "Comparison of total phenolic contents and antioxidant activities of turmeric leaf, pandan leaf and torch ginger flower," International Food Research Journal, vol. 17, pp. 417-423, 2010.

[19] T. D. Widyaningsih, I. Z. Zumroh, and N. Rochmawati, "Effect of mixed grass jelly (Mesona palustris BL.) and other ingredients effervescent powder in diabetic rats," International Journal of Technical Research and Applications, vol. 2, no. 5, pp. 52-55, 2014.

[20] A. L. Waterhouse, "Determination of total phenolics," Current Protocols in Food Analytical Chemistry, pp. I1-I8, 2002.

[21] S. Sreelatha and P. R. Padma, "Antioxidant activity and total phenolic content of Moringa oleifera leaves in two stages of maturity," Plant Foods Human Nutrition, vol. 64, pp. 303-311, 2009.

[22] I. F. Benzie and J. J. Strin, "The ferric reducing ability of plasma (FRAP) as a measure of antioxidant power: the FRAP assay," Analytical Biochemistry, vol. 239, pp. 70-76, 1996.

[23] J. Lee, R. W. Durst, and R. E. Wrolstad, "Determination of total monomeric anthocyanin pigment content of fruit juices, beverages, natural colorants, and wines by the $\mathrm{pH}$ differential method: collaborative study," Journal of AOAC International, vol. 88, no. 5, pp. 1269-1278, 2005.

[24] M. A. Papandreou, A. Dimakopoulou, Z. I. Linardaki et al., "Effect of a polyphenol-rich wild blueberry extract on cognitive performance of mice, brain antioxidant markers and acetylcholinesterase activity," Behavioural Brain Research, vol. 198, no. 2, pp. 352-358, 2009.

[25] S. Sungkamanee, J. Wattanathorn, S. Muchimapura, and W. Thukham-mee, "Antiosteoporotic effect of combined extract of Morus alba and Polygonum odoratum," Oxidative Medicine and Cellular Longevity, vol. 2014, Article ID 579305, 9 pages, 2014.

[26] S. Okuda, B. Roozendaal, and J. L. McGaugh, "Glucocorticoid effects on object recognition memory require trainingassociated emotional arousal," Proceedings of the National Academy of Sciences of the United States of America, vol. 101, no. 3, pp. 853-858, 2004.

[27] G. Paxinos and C. Watson, The Rat Brain in Stereotaxic Coordinates, Elsevier, Amsterdam, 2009.

[28] J. Lu, D. M. Wu, Y. L. Zheng, B. Hu, and Z. F. Zhang, "Purple sweet potato color alleviates D-galactose-induced brain aging in old mice by promoting survival of neurons via PI3K pathway and inhibiting cytochrome C-mediated apoptosis," Brain Pathology, vol. 20, no. 3, pp. 598-612, 2010.
[29] O. H. Lowry, N. J. Rosebrough, A. L. Farr, and R. J. Randall, "Protein measurement with the folin phenol reagent," Journal of Biological Chemistry, vol. 193, no. 1, pp. 265-275, 1951.

[30] G. L. Ellman, K. D. Courtney, V. Andres Jr, and R. M. Feather-Stone, "A new and rapid colorimetric determination of acetylcholinesterase activity," Biochemical Pharmacology, vol. 7, pp. 88-95, 1961.

[31] P. Thiraphatthanavong, J. Wattanathorn, S. Muchimapura et al., "Preventive effect of Zea mays L. (purple waxy corn) on experimental diabetic cataract," BioMed Research International, vol. 2014, Article ID 507435, 8 pages, 2014.

[32] W. Kirisattayakul, J. Wattanathorn, T. Tong-Un, S. Muchimapura, P. Wannanon, and J. Jittiwat, "Cerebroprotective effect of Moringa oleifera against focal ischemic stroke induced by middle cerebral artery occlusion," Oxidative Medicine and Cellular Longevity, vol. 2013, Article ID 951415, 10 pages, 2013

[33] S. M. Courtney, L. Petit, J. V. Haxby, and L. G. Ungerleider, "The role of prefrontal cortex in working memory: examining the contents of consciousness," Philosophical Transactions of the Royal Society B, vol. 353, no. 1377, pp. 1819-1829, 1998.

[34] A. Blokland, "Acetylcholine: a neurotransmitter for learning and memory?" Brain Research Review, vol. 21, no. 3, pp. 285-300, 1995.

[35] M. Ulas and M. Cay, "The effects of 17beta-estradiol and vitamin $\mathrm{E}$ treatments on oxidative stress and antioxidant levels in brain cortex of diabetic ovariectomized rats," Acta Physiologica Hungarica, vol. 97, no. 2, pp. 208-215, 2010.

[36] M. Singh, E. M. Meyer, W. J. Millard, and J. W. Simpkins, "Ovarian steroid deprivation results in a reversible learning impairment and compromised cholinergic function in female Sprague-Dawley rats," Brain Research, vol. 644, no. 2, pp. 305-312, 1994.

[37] M. Da Silva Morrone, C. E. Schnorr, G. A. Behr et al., "Oral administration of curcumin relieves behavioral alterations and oxidative stress in the frontal cortex, hippocampus, and striatum of ovariectomized Wistar rats," The Journal of Nutritional Biochemistry, vol. 32, pp. 181-188, 2016.

[38] C. T. Curtis, "The effects of prefrontal lesions on working memory performance and theory," Cognitive, Affective \& Behavioral Neuroscience, vol. 4, no. 4, pp. 528-539, 2004.

[39] Z. Alrefaie, "Vitamin D3 improves decline in cognitive function and cholinergic transmission in prefrontal cortex of streptozotocin-induced diabetic rats," The Medical Journal of Cairo University, vol. 81, no. 2, pp. 25-31, 2013.

[40] Y. Chudasama, J. W. Dalley, F. Nathwani, P. Bouger, T. W. Robbins, and F. Nathwani, "Cholinergic modulation of visual attention and working memory: dissociable effects of basal forebrain 192-IgG-saporin lesions and intraprefrontal infusions of scopolamine," Learning \& Memory, vol. 11, no. 1, pp. 78-86, 2004.

[41] J. M. Gutierres, F. B. Carvalho, M. R. Schetinger et al., "Protective effects of anthocyanins on the ectonucleotidase activity in the impairment of memory induced by scopolamine in adult rats," Life Sciences, vol. 91, no. 23-24, pp. 1221-1228, 2012.

[42] K. P. Giese and K. Mizuno, "The roles of protein kinases in learning and memory," Learning \& Memory, vol. 20, no. 10, pp. 540-552, 2013. 
[43] B. González, M. Raineri, J. L. Cadet, E. García-Rill, F. J. Urbano, and V. Bisagno, "Modafinil improves methamphetamine-induced object recognition deficits and restores prefrontal cortex ERK signaling in mice," Neuropharmacology, vol. 87, no. 1, pp. 188-197, 2014.

[44] P. Kaewkaen, T. Tong-Un, J. Wattanathorn, S. Muchimapura, W. Kaewrueng, and S. Wongcharoenwanakit, "Mulberry fruit extract protects against memory impairment and hippocampal damage in animal model of vascular dementia," EvidenceBased Complementary and Alternative Medicine, vol. 2012, Article ID 263520, 9 pages, 2012. 


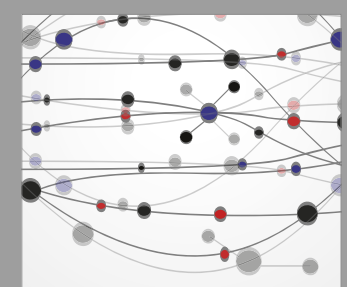

The Scientific World Journal
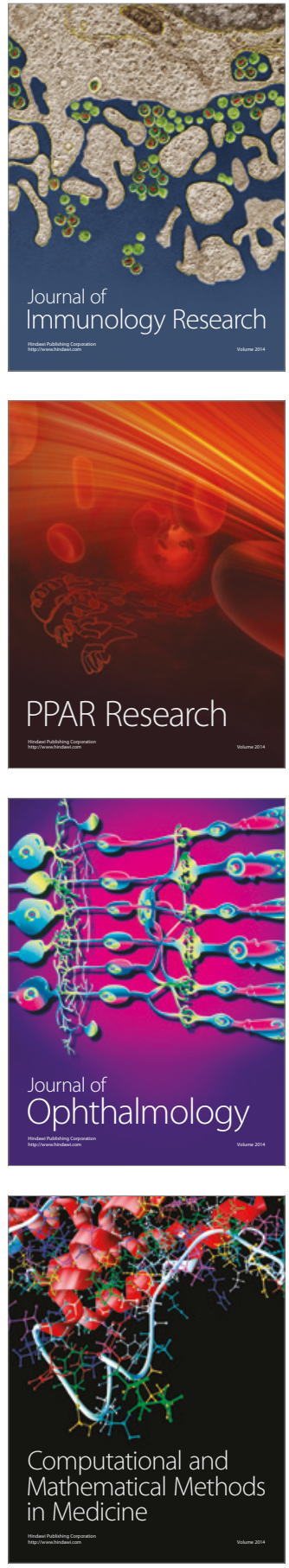

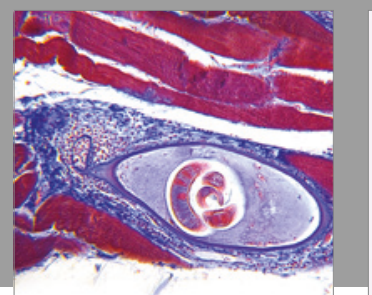

Gastroenterology Research and Practice
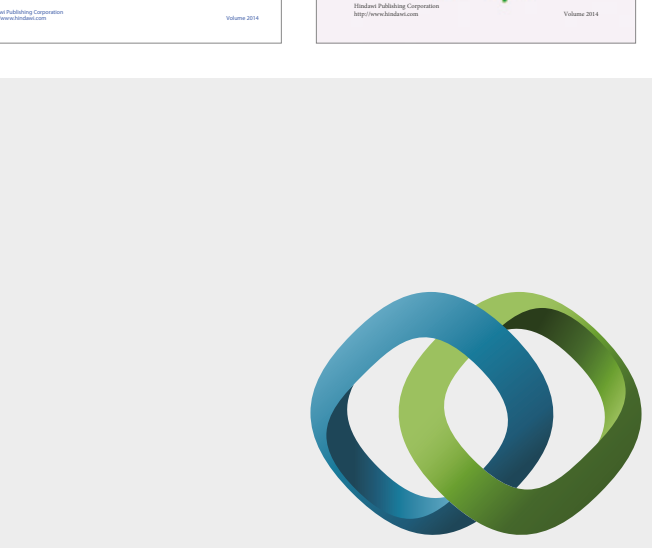

\section{Hindawi}

Submit your manuscripts at

https://www.hindawi.com
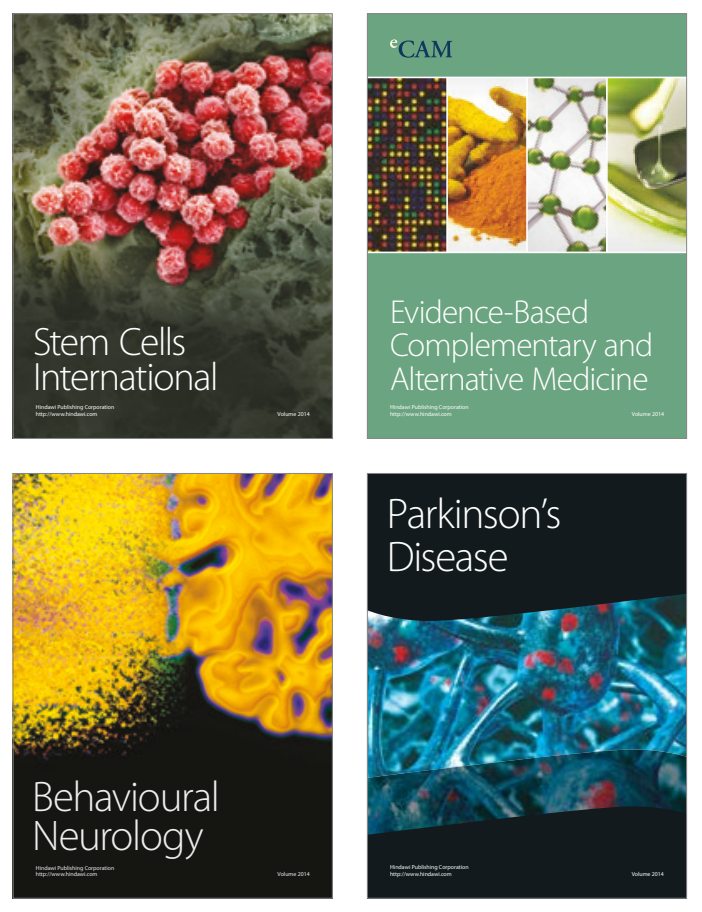
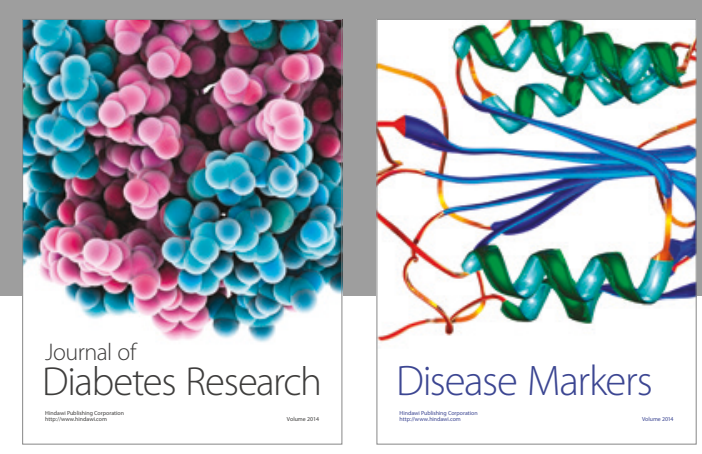

Disease Markers
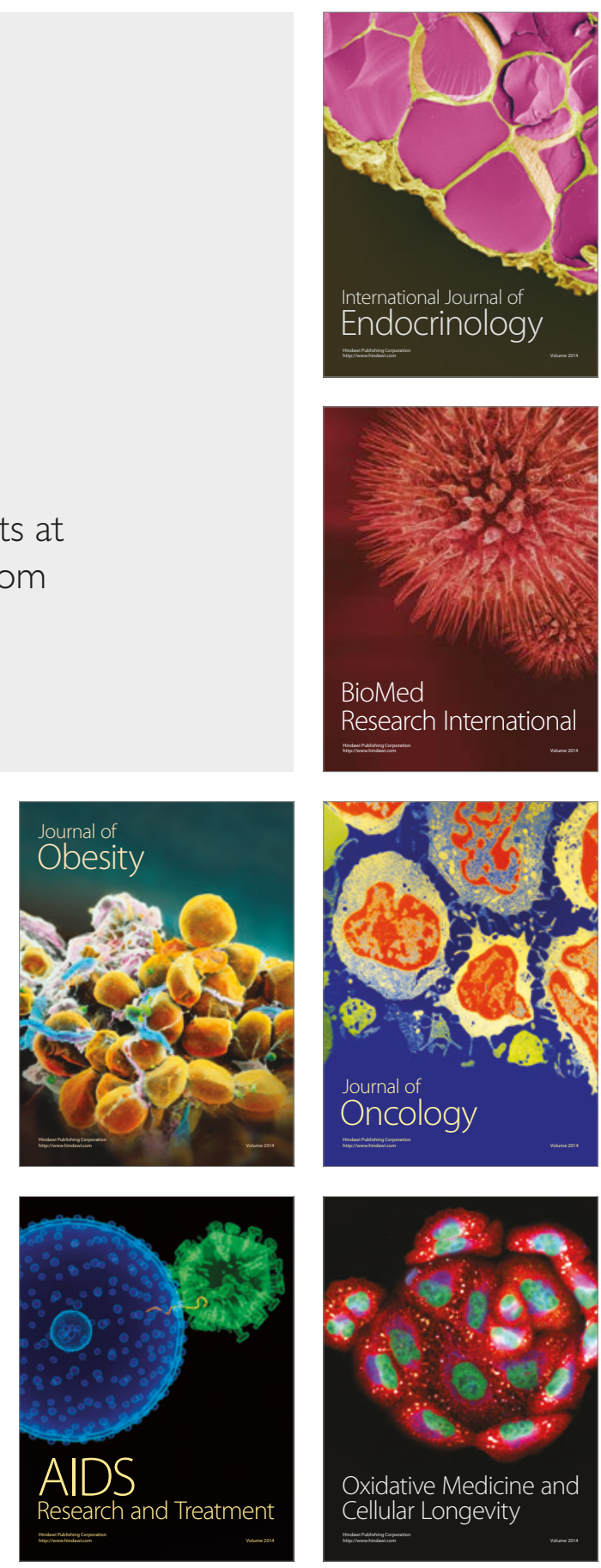